\title{
Práticas locais em clínica e educação: compromissos com a atual América
}

\author{
Local practices in education and clinical psychology: \\ commitments to today's America
}

Prácticas locales en clinica y educación:
compromissos com la América actual

ANA LUISA TEIXEIRA DE MENEZES*

VIVIANE FERNANDES SILVEIRA** \begin{abstract}
$\diamond$
RESUMO

A experiência de 12 anos de contato e de pesquisa com os Guarani ${ }^{1}$, através de pesquisas acerca da dança Guarani ${ }^{2}$, além dos estudos "Infâncias e educação Guarani"3 e "Pensamento originário e mestiço: caminhos decoloniais na formação acadêmica da educação e da psicologia"4, tem oportunizado que se pense o lugar da atual América, os trabalhos clínicos, de educação em diálogo com a ciência moderna, tendo em vista o projeto científico no campo da psicologia e da educação que evidenciam as práticas locais. Por meio da obra de Rodolfo Kusch, propõe-se uma intersecção, desde um ponto de vista situado não apenas geograficamente.
\end{abstract}

Palavras-chave: América. Psicanálise. Educação. Psicologia clínica.

\begin{abstract}
The experience of twelve years of contact with the Guarani people, though the researches about the Guarani dance, "Childhood and Guarani Pedagogy" and the "Originary and mestiss thinking: decolonial pathes on the academic formation in pedagogy and psychology", has provided us opportunities to think the current America, the clinic activities, on pedagogy on dialog with the modern science, considering the scientific project and pedagogy showed by our local practices. Though Rodolfo Kusch's work we propose an intersection, since a point of view placed not only geographically.
\end{abstract}

Keywords: America. Psichoanalyses. Pedagogy. Psychological clinic.

\section{RESUMEN}

La experiencia de doce años de contacto con los guaraníes, a través de la investigación sobre la danza Guaraní, "La infancia y la educación Guarani" y el "Pensamiento originario y mestizo: caminos decoloniales en la formación académica en pedagogía y psicología" nos tiene oportunizado pensar el lugar de la actual América, los trabajos clínicos, en pedagogía en dialogo con la ciencia moderna, teniendo en cuenta el proyecto científico en el campo de la psicología y pedagogía que evidencian nuestras prácticas locales. A través de la obra de Rodolfo Kusch proponemos una interacción desde un punto de vista no sólo geográficamente situada.

Palabras clave: América. Psicoanálisis. Pedagogia. Psicología clínica.

\footnotetext{
*Doutorado em Educação na UFRGS, professora do Departamento de Psicologia e do Programa de Pós-Graduação em Educação da UNISC. E-mail: $<$ luisa@unisc.br>.

**Pós-doutorado em Educação na UNISC, psicanalista, membro da Escola de Estudos Psicanalíticos. E-mail: <xereramaviviane@gmail.com>.

1 Convencionou-se utilizar neste texto a palavra "Guarani” para a etnia Guarani Mbyá, presente na região Sul do Brasil.

2 Sobre dança e educação Guarani, aprofundou-se no livro Educação ameríndia: a dança e a escola Guarani, as teses das pesquisadoras Ana Luisa Teixeira de Menezes (UNISC) e Maria Aparecida Bergamaschi (UFRGS).

3 Projeto de pesquisa "Infâncias e educação Guarani", coordenado pela Dra. Ana Luisa Teixeira de Menezes, vinculado ao programa de Pós-Graduação em Educação da Universidade de Santa Cruz do Sul - UNISC e financiado pela FAPERGS, edital Gaúcho 2013.

4 Projeto de pós-doutorado de Viviane Silveira, iniciado em 2013, no Mestrado em Educação da UNISC, sob a orientação de Ana Luisa Teixeira de Menezes.
} 


\section{REFLEXÕES INTRODUTÓRIAS}

A educação e a prática clínica e seus encontros com o que as viabiliza, a cultura, não podem não trazer para dentro de seu trabalho a questão das particularidades locais. Escutar pessoas, na região Sul do Brasil, que buscaram atendimento para tratar de aspectos psíquicos e, principalmente pesquisar com os Guarani fez com que se interrogasse como pensar, teorizar e intervir. Uma vez que as lógicas de pensamento inconsciente não pareciam desvinculadas de heranças culturais mais antigas e não ocidentais. A preocupação quanto a entender e escutar e a busca por uma estrutura de linguagem teórica que tivesse particularidades para contemplar esses elementos foram as motivações para essa busca.

Tanto a convivência com o povo Guarani, na região Sul do Brasil, quanto a busca por aprender com os indígenas e autores como Rodolfo Kusch (2006), serviram como fortes elementos para escutar, para a transdisciplinaridade, para compromissos com a coletividade. Mas, sobretudo, escutar. Esse autor fala do fedor da América, da reação do universitário pulcro diante do fedor da América. O fedor, diz, está em cada um. Mas o que fazer com esse lugar, caverna da universidade que se habita? Filósofo do estar-sendo, ensina que não há como ser sem estar. Diz que, nos povos originários, impera a lógica do estar, da contemplação, do vegetal, do reverso do pátio dos objetos, da fagocitação, enquanto mecanismo de apropriação e resistência. E que há muito antes e depois da ciência moderna, da higiene bacteriológica, da acumulação e do controle, da pequena história.

Kusch (2000) realiza uma compreensão do pensar americano. Propõe categorias como o mero estar, enquanto fundo do pretender ser alguém, e que sempre termina por engoli-lo, lugar de legitimação da transitorialidade, do viver, do sentir, do saber comunitário, das tradições. Fala da contemplação ou do estado especial de concentração em que a conexão consigo e com o cosmos passa por outros lados que não o da racionalidade. Introduz o demonismo vegetal ou tudo aquilo que perturba o sentido retilíneo da ação e da cidade e que prioriza o fluxo das conexões. Ou, como diz o autor acima citado, a dimensão da árvore que poderia ter sido qualquer coisa, como um peixe ou uma alga. Ele também apresenta o pátio dos objetos ou uma imagem para o que se herdou da moral romana, acumulativa, material, das propriedades e da pulcritude, desde onde a ira dos deuses deslizou para a ira dos mercadores. Trata, ainda, da noção do mestiço, da lógica de um continente que defende sua impermeabilidade, significante mestre que conduz a possibilidades de resolução. Para explicá-lo, invoca a imagem da serpente emplumada, penetração dialética de opostos, vida engendrada na ambivalência. Ribeiro
(1995) diz que é onde se fez e vai se continuar fazendo, que coube a cada um inventar um novo gênero de gente, diferente das tantas quantasexistam. Admite que se é um povo impedido de sê-lo, mestiço na carne e no espírito.

Kusch (2000), em "De la mala vida porteña", esclarece que podem ter feito o índio desaparecer enquanto coisa, mas jamais enquanto estrutura. O mesmo autor (2000, p. 367), em "La salida del índio", retoma a expressão local argentina "saiu-lhe um índio", tratando do polimento que percebe existir, inicialmente, em sua sociedade. Mas quando este se quebra, nesses momentos, em especial, quando vem à tona uma manifestação de indignação e defesa quanto a algo sagrado para alguém, assim o nomeiam.

Ressalta-se, ainda, a importância do diálogo com autores da decolonialidade, como Santos (2010), que discute o processo de submissão e de monopólio epistemológico dos saberes e dos problemas existenciais; e Mignolo (2006), que reflete em torno de uma mudança de concepção de ciência. E que assim se possa rever a vergonha e o sentimento de inferioridade que a América carrega consigo e em seus modos de pensar, viver e sentir, o que leva a pensar numa necessidade de decolonialidade do sentimento.

Isso implicou, no mínimo, uma responsabilidade para com o campo dos tratamentos, das formações, mas, também, quanto aos próprios povos originários, entender que posição cabe a cada um. Quando se escuta no consultório ou nos espaços urbanos de tratamento, que gramática nos serve? Quando se transmite a própria formação, que posição se ocupa? Quando se vai às comunidades originárias, que cuidados, que encaminhamentos, que discussões, que trabalhos e que soluções se devem a eles? A quem e ao que responder nesse âmbito?

Neste artigo, propõe-se uma discussão sobre estes três pontos: aspectos clínicos, aspectos da educação e da formação profissional e aspectos do tema do trabalho de campo.

\section{SObRE A CLÍNICA NO SUL}

A psicanálise, germinada em terras ocidentais e levada a outros territórios, ensina que todos são sempre pessoas construídas dentro de uma coletividade. As vivências clínicas trazendo situações, significantes e lógicas de pensamento, que não foram as mesmas vistas pelos criadores da psicanálise, ao longo dos anos, na experiência do autor deste estudo, fizeram-se escutar enquanto formas relevantes de expressão que demandavam outras leituras. A preocupação com a recusa dos elementos subjetivos continuados na atualidade cultural e não contemplados pelas teorias dos tratamentos de saúde mental também 
inspirou reflexões sobre responsabilidade e ética com a prática clínica.

Percebe-se, na prática cotidiana clínica, uma série de tonalidades, ritmos, movimentos e modos de pensar a vida que levam a um campo de perguntas sobre que especificidades poderiam existir em termos subjetivos. Chegam a questionar a relevância de outros formatos teóricos a partir de mais estruturas de pensamento que aqueles exclusivos do modo ocidental. A psicanálise, em toda sua trajetória, sempre apontou para a inexorável importância de aspectos culturais enquanto lugar de enlace para a construção da pessoa. Nesse caso, não se tinha como não trazer inquietações sobre que palavras se devem aos modos de pensar no local em que se vive, uma vez que este se encontra tão fundamentalmente atravessado por elementos culturais específicos e irrecusáveis.

Quando pessoas vêm solicitar escuta, com frequência, há alguns anos, percebem-se elementos de ancestralidades, enquanto aspectos que podem colaborar e precisam ser escutados e teorizados. Modos diferentes de tratar a frequência, o pagamento, as formalidades e a atmosfera clássica de tratamento fizeram com que se questionassem alguns paradigmas. De um lado, esse giro se dá em função de vozes que insistem, persistem e se fazem audíveis. De outro lado, a entrada em contato com outras teorias e com os próprios indígenas, fez com que se reconhecesse não apenas sua sabedoria e diretrizes fundamentais para os tratamentos do mundo emocional, como também que muito do que eles viviam tão amplamente em suas culturas preservadas, também se vive, reconhecendo-se ou não.

Ao conviver com os Guarani e com seu extremo perfeccionismo, rigor à palavra e ao silêncio, cuidados extremos com a dimensão dos excessos, assim como a maneira peculiar de lidar com a falha e aspectos incomparáveis de indestrutibilidade simbólica, reconhece-se, por exemplo, que seria possível se aprender com as expressões e ética da vida presentes na natureza. Que seria muito importante tomar esta última enquanto fonte simbólica e de ensinamentos. Experimentar novos níveis de contato com o semelhante humano, com o universo, com a linguagem, tal qual se vive quando se está com esses povos, fez com que se experimentassem novas dimensões de conexão sensível que não obedeciam sempre aos padrões urbanos. Fez com que se ficasse ainda mais silencioso, mais amoroso, tal qual mostram e fazem vivenciar os líderes espirituais originários. Fez também com que se duvidasse de alguns protocolos. Percebeu-se que a postura acolhedora e bastante concentrada em aspectos da ancestralidade, ao invés de se desfazer do lugar das formalidades, conferia respeito, confiabilidade e espaço para demanda mais apropriada ao ritmo de cada um e de suas verdades.
A aproximação dos ensinamentos que trazem aspectos ligados à coletividade, à consideração do mundo e das formas de vida sem priorizar a humana, às noções de respeito aos mais velhos, à autonomia e relativização de aspectos ligados à propriedade, à monogamia, à finitude como percebe a ciência ocidental e à importância dada à linguagem escrita, são elementos nessa mudança de vetores. Não enquanto excludentes da cultura convencional, mas enquanto posição que leva em consideração aspectos mais antigos, atuais e de muita seriedade para pensar a vida humana também.

Os teóricos originários e os teóricos urbanos que escrevem sobre os originários ressaltam que, do ponto de vista espiritual, deve-se trabalhar para que se encontre o melhor de cada um, os pontos comuns entre aspectos ancestrais recusados e atualidades urbanas, que se possa ser capaz de falar disso. E, sobretudo, que se possa exercitar o que chamam de coração profundo do homem, regulador intuitivo, que não tem etnia, que leve à conexão com o mundo em suas luzes e sombras, bens e males. que se converta em um caos interior e que acompanhe com sensibilidade essa regulação que a própria vida é capaz de operar.

A presença dos povos originários em suas comunidades enquanto culturas preservadas e resistentes é prova irrefutável de seu sucesso em termos de modo de viver. Alegria, possibilidade de convivência em grupo, inteligência diferenciada, desejo de aprender e afetividade são marcos que definem o campo e o patamar de resolução que possuem para as adversidades da vida. É inevitável se pensar em demandar-lhes ensinamentos e perguntar do que se sabe sem saber, enquanto herdeiros dessas culturas. Assim como acerca do que se precisa exercitar para melhor viver, para produzir mais saúde, mais cura, mais vida. Compreendem-se os princípios de educação, formação da pessoa e filosofia originárias, enquanto princípios de cura em si. Entende-se a busca por formar-se nesses ensinamentos como dispositivos clínicos por excelência.

Jecupé (2002) afirma que, no mundo Guarani de onde vem, todo dia é guerra mundial. Relata as intermináveis situações de despedida, violências e adversidades que seu povo sofre e localiza na criação e, sobretudo no mecanismo do perdão, oferecendo ensinamentos sobre seus modos de curar o homem branco, enquanto saída para o que viveu. Fazer vencer o amor ao ódio e a vida à morte são ensinamentos psicanalíticos e analíticos. Mas como será que, em seus cotidianos, esses povos resolvem isso e tornam-se tão poderosos quanto encantadores?

Kusch (2000) fala da fagocitação, da transculturação, em que uma realidade aparentemente invadida e ameaçada por outra cultura a canibaliza, apropriando-se do novo sem se desfazer do próprio, toma o que se apresenta do território 
alheio que se abriu em seu território e transforma em algo mais uma vez seu. Trata-se da arte do engendramento que supera uma contradição. A noção de fedor de América, metáfora profunda do outro que causa transtorno íntimo, que nubla a visão, perturba a razão, infiltra-se na cultura, que ainda não assumiu um rosto próprio. Refere-se ao que cheira mal da constituição francesa imposta aos povos indígenas e imigrantes vorazes e desgastados, do império construído em cima de milhares de corpos, do equivalente ao mundo do diabo, dos santos, dos deuses, do que não é do homem, do tigre, do trovão e da tempestade.

Quando se escuta sobre práticas e crenças não ocidentais, de pessoas muito bem situadas simbolicamente e em suas ancestralidades não ocidentais; quando se escuta sobre outros modos de viver as trocas conjugais que não a monogamia, sobre a relativização de bens materiais e higiene convencionais; quando se escuta sobre intuição; quando se escuta a palavra e a densidade do silêncio como ensinaram os Guarani em suas estratégias políticoespirituais; quando se sonha no formato dos sonhos xamânicos que são experienciados nas aldeias, não se pode recusar que se é plataforma entre o pensamento causal e o seminal.

Não se acredita, caso os fundadores da psicologia analítica e da psicanálise vivessem nessas latitudes ao sul, que não pesquisariam e não se colocariam em posição de aprendentes quanto aos mais antigos aqui, ao mais antigo que há em cada um e, sobretudo, ao que, em algumas regiões, está escrito no corpo materialmente e no povo. É preciso haver a disposição para ouvir, nos encadeamentos que trazem sentidos simbólicos, longe de um funcionamento que ocorra exclusivamente nas teorias que cruzaram o Atlântico. Não é possível não se falar disso na clínica analítica e psicanalítica. Seria como andar pelas ruas em que todos se dizem euro-descendentes e recusar os muitos nomes de ruas e hábitos e histórias originárias que estão por toda parte.

A sensibilidade originária também está no povo atual. Praticar uma clínica que exercite essa sensibilidade das conexões, do coração profundo, do que relativiza parâmetros capitalistas e científicos, parece bastante bem recebido por muitos. As pessoas entendem quando são olhadas com o coração. Elas respeitam quando se fala que se trata no consultório, mas se aprende com os Guarani. Elas permanecem quando se pratica uma clínica mais em movimento e menos nos ritmos convencionais. Elas compreendem o nível de implicação que se tem com elas quando esses outros parâmetros entram em cena.

Esse é um caminho que exige muita dedicação e coragem. Coragem de se dizer mestiço, de afirmar fazeres desde outros lugares. Mas o que será que isso quer dizer? Ensina-se que a fagocitação não é cópia. É a grande história, pedagogia da terra, trocas profundas, clínica situada, palavra grande. Como se trabalhar tudo isso entre os profissionais da saúde mental?

\section{SOBRE EDUCAÇÃO E FORMAÇÃO PROFISSIONAL}

O encontro com a cosmologia Guarani, a partir das crianças, no projeto "Infâncias e educação Guarani”, tem se revelado como encontro com a palavra antiga que os Guarani não querem esquecer, pois diz respeito ao sentido da casa, da morada dos saberes (MENEZES, RICHTER, 2014). A Opy como a "universidade" dos Guarani e a aldeia como lugar de educação coletiva, na qual cada um pode encontrar o melhor de si mesmo, apontam tanto para valores educacionais, sustentados em uma poética e em uma ética enraizadas no "estar sendo" da filosofia ameríndia de Kusch (2000), quanto para fontes de um pensamento que mesclam a cotidianidade com o misterioso e transcendente. O livro bilíngue, denominado Nhandereko Kue Kyringue'í Reko Rã - Nossa história para as crianças (MENEZES, RICHTER, SILVEIRA et al. 2015), decorrente da pesquisa acima citada, mostra que a convivência nas escolas de duas aldeias Guarani emerge como disparador para um diálogo entre velhos, jovens e adultos Guarani e não Guarani, na vivência de aprendizados que pulsam intensamente entre a palavra do estar sendo ameríndio e do ser ocidental.

Kusch (2000) faz lembrar do sentido de uma América Profunda, que inclui um modo de pensar, de viver e de filosofar, profundamente presente no modo de vida popular, atual, mestiço e indígena. $\mathrm{O}$ autor se refere a um modo de conhecer, de um estar sendo, como fluxo intercultural, tão profundo, tão misturado e que, por isso, torna-se tão invisível à visão que se tem de conhecimento. É o que Bergamaschi (2015) descreve em seus estudos da educação indígena com os Guarani, quando revela que não existe a categoria do ensino e sim a do aprender. Uma aprendizagem que, para Menezes \& Bergamaschi (2015), em seus estudos sobre a dança Guarani, é relatada na gestualidade das crianças e na espontaneidade de movimentos que emergem da curiosidade, da atenção ao desejo de saber e participar do mundo. Aprendizagem que está diretamente ligada a uma estética pautada na atenção à escuta do mundo, à manifestação da palavra sagrada, à espiritualidade e à corporeidade.

Yo yá no soy más yo. A frase de Che Guevara foi trazida recentemente por Rossi (2014) para tratar de sua travessia iniciática pela América, durante a qual ele deixa de ser Dr. Guevara para tornar-se Che. Falava de vivências que, quando se dão, são definitivas, de uma transformação possível, da busca por se intuir quem se é, como se chega a ser quem se é, enquanto se assuma ou se fabrique um caminho, um algo acerca da dignidade de se 
conquistar pessoalmente, cada um, um lugar não apenas situado geograficamente, mas enraizado em uma história específica.

A vivência de aproximação do pensamento kuschiano e, em seguida, a convivência profunda com os Guarani fizeram com que se caminhasse rumo a formulações e lugares possíveis para cada um, para as formações profissionais na área da saúde mental, para a urgência de se nomear realidades intermediárias, tensionadas, contraditórias, de quem escuta, vive, ancestraliza, canibaliza, desliza pelas raízes profundas do inconsciente vegetal americano. Tasat (2013) ensina que existe uma valentia pontual em se assumir algo novo, desde o lugar de mestiços, assim como, retornando ao pensamento kuschiano, a caverna da universidade, esta que se habita, seria crucial inventar outra coisa. Algo mais próximo da vida, algo menos artificial e distanciado da lógica da terra.

Inventar o mundo outra vez, dentro dessa proposta, parece, de um lado, fazer pensar e formular o lugar da plataforma de continuidade; e, de outro, teorizar o encontro com as fronteiras mais extremas, quando das trocas diretas nas comunidades. Quando se dedica a falar para estudantes na universidade, quando se fala com o povo sobre o tema do pensamento decolonial, invariavelmente encontra-se surpresa, respeito, interesse, escuta delicada e atenta. Muitos, após vivências iniciais nas comunidades, relatam transformações importantes ${ }^{5}$. Tem-se a certeza de que a fertilidade desse tema é imensa e que a potência desse encontro é definitiva.

Do lado de alguns espaços com os quais já se contou, por exemplo, o Seminário de Idioma e Cultura Guarani, coordenado pelo Prof. Vherá Poty ${ }^{6}$, assim como outros de interlocução direta com os intelectuais Guarani na construção sobre formação para professores, deparou-se sempre com um encantamento. Não apenas com a rara oportunidade de escutar tais sábios, mas também com a comoção pela chance de acessar notícias sobre modos de viver mais genuínos e que legitimam a vida dentro de cada um no campo da interciência (LITTLE, 2010), aquela que inclui os saberes indígenas no campo científico e acadêmico.

Quando estudantes em formação vão às comunidades, como nas vivências na Unisc e na UFRGS, assim como quando foram realizados encontros entre crianças da cidade com crianças originárias, promovidos entre escolas, assim como quando se contou com espaços de fala desses pensadores em mais seminários acadêmicos,

\footnotetext{
${ }_{5}$ Destaca-se um exemplo de uma aluna de Psicologia que passa a valorar positivamente sua história e infância, antes trazida com um sentimento de vergonha e invisibilidade, a partir do contato com a aldeia Guarani no encontro intercultural indígena promovido pelo cacique Vherá Poty, na aldeia de Itapuã, situada em Viamão.

6 Curso de extensão de Idioma e Cultura Guarani oferecido pelo PPGEDUUFRGS a partir de 2012/2.
}

do mesmo modo, as sementes costumam cair em solo fértil. Costumam ser escutadas e bem tratadas, mesmo que haja o embaraço intercultural, os eventuais desacertos quanto a como lidar com diferenças, negociações, culpas, limites das fronteiras, o que pensar sobre o lugar de cada um, já que não se construiu, originalmente, para pensar sobre isso.

A partir dessas ideias e da pesquisa "Infâncias e educação Guarani”, pensou-se sobre a troca psíquica e sobre a formação educativa que tem acontecido entre pesquisadores, professores e estudantes e o povo Guarani, na forma como trocam seus sonhos e percepções. Tanto na experiência de professoras como na dos estudantes de graduação, de mestrado e de pós-doutorado, percebeuse que os Guarani vivem com intimidade os mundos simbólicos. Por acreditarem, valorizam as palavras, os sonhos, as visões, os símbolos que emergem no caminho de individuação; valorizam a própria individuação, vivendo a educação e a formação da pessoa, como uma integração do Si-mesmo, como desenvolve Jung (2013), enquanto um centro da psique, uma fonte de autorregulação entre o ser e o transpessoal, capaz de gerar saídas criativas com grande poder de cura.

Todo esse processo acontece quando existe um campo inconsciente que vai constelando, no sentido de revelar o que está latente. Conforme fala Campbell (1990, p. 61), um xamã exerce o poder de cura naqueles que o legitimam e que desejam ser curados por ele. É nessa relação de legitimidade entre o que deseja ser curado e o que cura que o processo simbólico é fertilizado "no que está aguardando ser trazido à tona". Assim vão se formando os curandeiros Guarani, numa relação entre pessoa e coletivo.

Os dispositivos que se tem tido a oportunidade de vivenciar no Rio Grande do Sul acerca dessas trocas têm sido as aproximações acima mencionadas. Os convites para falas, as visitas às aldeias. Contou-se com o privilégio de se estar próximo, fisicamente, das comunidades originárias, no estado do Rio Grande do Sul.

As crianças que se aproximam, por exemplo, que têm oportunidade de entrevistar ou estar com os Guarani, costumam trazer suas curiosidades sobre o cotidiano cultural e sobre o modo de viver a educação, e apresentar algo da distância que os eventos históricos causaram. Perguntas sobre o que comem ou sobre o que vestem, como compreender que tenham aparelhos eletrônicos com eles, são efeitos ocasionados pela falta de convivência com regiões atravessadas por um processo de branqueamento mais forte que a maioria. Inicialmente, vivenciam a realidade originária enquanto algo distante, obscuro, estranho.

No entanto, um dia, na aldeia ou mesmo em um turno de atividade na escola Guarani, costuma produzir 
efeitos significativos. Conexão, enlace, trocas lúdicas e aprendizagens linguísticas, desconstrução de muitas dessas imagens iniciais de distanciamento. Assim como ocorre a eclosão da alegria com a descoberta de novas passagens pelos caminhos do universo. Aspectos ligados à liberdade das vivências com a natureza, outras realidades corporais, quebras de regras e dogmas das trocas esportivas, surpresa e aprendizagem com a tranquilidade e afetividade são aspectos que se repetem.

Os estudantes de graduação e demais profissionais que vivenciam a oportunidade de estar com os milenares costumam relatar, primeira e frequentemente, algumas questões: a imagem inicial de que as comunidades vivem em um estado de pobreza, assim como questões com aspectos de suposta falta de higiene e cuidados corporais transformam-se durante os contatos. A alegria, a força, a inteligência e o nível de interação das crianças costumam impressionar muito. $\mathrm{E}$ a coerência, o silêncio e a dignidade com que costumam se apresentar esses povos desmancham de saída muitos conceitos, frutos de desconhecimento profundo.

Do mesmo modo que as marcas das vivências com os originários diretamente operam registros subjetivos definitivos, assim também os estudos, as discussões sobre autores que pensam o decolonial e o lugar cultural de cada um neste mundo são marcos irreversíveis. A discussão de casos clínicos e educativos, por exemplo, com grupos de estudantes de Psicologia e Educação, sinalizando a necessidade de se repensarem leituras clínicas de situações de tratamento de pessoas situadas em outra realidade cultural que não europeia, faz com que repensem suas próprias heranças familiares. Estas, questões pessoais que não gostariam que fossem tratadas ao modo da ciência ocidental, assim como suas responsabilidades em receber estudantes e trabalhar na formação de crianças em sala de aula, as quais vêm com caminhos subjetivos mais ou menos evidentes dentro do que se apontou, mas que, uma vez escutados, sinalizados, não silenciam mais.

Numa discussão na aldeia Guarani de Salto do Jacuí, no interior do Rio Grande do Sul, com professores indígenas, não indígenas, alunos de mestrado em Educação e lideranças Guarani, evidenciou-se a riqueza de valorizar as diferenças culturais e aprender modos de estar Guarani, conforme explicita João?: "Apressar demais o pessoal vai fazer desistir e ir embora, como foi o meu caso".

Nesse momento, aprendeu-se sobre o tempo, sobre o ritmo diferenciado e sobre a pressa que se possui no viver, como uma aceleração interna que produz ansiedade e rótulos para quem não segue a rapidez da aprendizagem

\footnotetext{
${ }^{7}$ Cacique João Acosta, líder da comunidade de Estrela Velha e um dos organizadores do livro Nhanderekoa Kué Kyringue'i Re Korã, nossa história para as crianças, juntamente com Ana Luisa Menezes, Sandra Richter, Viviane Silveira e Roberto Fernandes.
}

ocidental. Outro aspecto discutido e apreendido sobre a aprendizagem é a perspectiva que o Guarani dá para o coletivo, o estar junto.

Uma vez que novos recursos de leitura são oferecidos nas formações, ao se emprestarem os próprios registros de paixão, de sensibilização, de reconhecimento sobre a grandiosidade desses temas, eles não voltam a se invisibilizar. O que os fazia irreconhecíveis antes era algo de uma recusa da herança da violência. Começar a falar implica começar a simbolizar. De fato, há uma linha que, após ser cruzada, não se volta atrás. O feitiço, a maldição, quebra-se. A cegueira da recusa é um mecanismo psíquico que exige uma ausência representacional.

Bergès e Balbo (2002) perseguem a pergunta sobre como nasce um registro representacional. Ensinam, a partir de suas práticas clínicas de vida inteira dedicada às crianças pequenas, que se trata de um jogo de posições subjetivas em que um adulto, mais frequentemente no início da vida, um cuidador, vai emprestando à criança seu aparelho de sonhar, seu corpo simbólico, seu masoquismo limitado. E vai fazendo borda, golpeando, sobretudo através da voz, afetando-a com seus registros representacionais para formar seu corpo, memória, percepção e pensamento. A cada golpe, uma vez respeitada uma série de condições necessárias, a criança vai ultrapassando as marcas alheias e tornando-se ela mesma capaz de pensar, desde as apropriações do que se deixou marcar pelo outro. Assim se formam os registros acerca da dor, do medo, da finitude, do sexual, das preferências, da capacidade do colocarse na pele do outro. A transmissão do silêncio acerca de um modo violento de seguir olhando uma cultura que é a transmissão dessa ausência representacional. Afetar com a musicalidade da voz, com a prosódia da gestualidade o que se aprende por meio do coração com os intelectuais decoloniais, incluindo os indígenas, é operar função materna e paterna. Não tem volta, porque, uma vez contornada a borda, a imagem unifica-se no espelho e haverá precipitação na pré-maturidade americana acerca de quem se é, e já se perdeu da colagem ao corpo colonial. Já se perdeu a filiação violenta. Já se é novo sujeito. Já se pode provocar e oferecer-se desde um outro lugar. Já se pode ser objeto do desejo. Não da demanda. Já se pode saber. E até ensinar.

No entanto, quando se entra no campo das fronteiras enquanto parte significativa do atual, mas também de lugares aos quais não se tem tanto acesso; lugares onde se encontram divergências lógicas, onde há os efeitos puros e diretos de um genocídio, onde muito mal é vivido hoje em meio ao tema das questões étnicas e territoriais, então, tem-se mais um novo trabalho. Além de se colocar na posição de quem não sabe de tudo e deseja aprender, maravilhado com o outro. Há mais um trabalho além de se perguntar quem se é, como mestiços 
herdeiros dos milenares e da invasão. É muito grande e muito complexo o que entra em cena. De fato, valentia é necessário. Mas também disponibilidade, gana de saber da verdade, força para tolerar as imensas incompreensões e as causas inesgotáveis. É necessário não estar nem de um lado, nem de outro, afirmar a escolha por uma posição nova, por um estar na fronteira. Misturar-se com o universo e converter-se em caos interior? Ancorados em que filiações? Como limitar onde termina(?) uma e começa outra? Quais as bordas das responsabilizações? $\mathrm{O}$ que fazer com a branquitude que resta? Com que cara afirmá-la? E, após tudo isso, com que crença sustentá-la? O drama da posição mestiça é bastante pontual. É necessário um olhar para ela.

Kusch (2000) fala das contradições. Os originários ensinam profundamente sobre elas todo o tempo. Ambos trazem recursos para pensar isso que os fundadores da psicanálise apontam como a própria lógica do funcionamento inconsciente. É bastante provável que aquilo que dizia o líder Guarani, em um determinado momento da convivência que se teve, "a psicanálise deve ser muito parecida com Guarani”, situe a posição originária, a vida e o inconsciente em uma mesma plataforma ou ao menos em algum bom nível de parentesco.

\section{A CONVIVÊNCIA COM OS GUARANI E OS PRINCÍPIOS PARA A CURA}

A alegria, a curiosidade, a tranquilidade, o tratamento respeitoso dado à palavra e ao silêncio, o senso de humor refinado, o ordenamento corporal, a possibilidade de viver em coletividade, a consideração particular da natureza e do ancestral, a afetividade e a resistência, são sinais de nível de constituição simbólica de uma cultura ancestral. São fatos impressionantes, pensando-se na sustentação desses elementos ao longo dos milênios e através de séculos de genocídio.

Evidentemente, a primeira pergunta que vem ao se deparar com uma realidade assim é: de onde esse povo tira seu poder? Em seguida: como se pode aprender com eles? E depois: como se podem estabelecer trocas para que se colabore com suas demandas? No entanto, diante dessa realidade de encantamento e desejo de avançar nessa trajetória, surge uma última questão: que aspectos subjetivos necessitarão de leitura para que as trocas sejam sustentáveis?

A hipótese é de que, em alguns aspectos, a psicanálise, com sua disponibilidade para o silêncio, para a escuta, para o tempo para o outro, para os cuidados éticos com a não positivação de lugar e com a posição de aprender com o outro, possa colaborar em algumas leituras. No entanto, não se possui prática ou teorização sobre outros modos de subjetivação (não ocidentais), assim como não se temteorização para o campo e para o lugar de alguém que trabalha com clínica quando está situado em novo cenário.

Não se trata de propor psicanálise às pessoas Guarani, tampouco psicanalisar uma comunidade. A percepção é de que a posição e a grandiosidade dos modos de curar desses povos não autorizariam que se propusesse um tratamento convencional. Ao contrário, a busca aqui é por aprendizagem e pela escuta acerca de uma troca que responda aos aspectos relevantes para o cotidiano das comunidades.

Desse modo, investiga-se que dispositivos clínicos e da teoria analítica e psicanalítica podem colaborar nesse encontro, seja naquilo que se aproxima em semelhanças quanto na possibilidade de reconhecer que se defronta com o próprio desconhecimento, só cabendo, assim, testemunhar os outros caminhos de pensar.

Acredita-se que trazer algo dessa pedra-angular da indestrutibilidade originária para os modos de pensar urbanos implica uma contribuição com esta última; um ato de respeito com os mais antigos e com a construção de vieses de funcionamento para todos que passem por compromissos com níveis mais altos de responsabilidade em relação à coletividade.

Os Guarani compreendem a palavra, som, melodia que faz viver as coisas enquanto elemento que corresponde à própria alma. Durante a gestação e o primeiro ano de vida, essa alma-palavra iria aos poucos assentando. Realizam a cerimônia de revelação do nome, em que um líder espiritual faz a leitura do milho ao longo de quatro noites e anuncia os nomes que são localizados como dessa criança e que correspondem a aspectos cruciais de sua personalidade. Ele também, através desse ato, aconselha os pais sobre sua educação (POTY; CHRISTIDIS, 2015).

É muito interessante pensar, por exemplo, sobre o efeito dos cantos realizados pelos Guarani e que são apresentados pelo coral infantil. O efeito da escuta das vozes parece de um nível de pungência e eloquência único. A alma parece responder inteira.

O tratamento é de alta seriedade. É de implicação espiritual. O que quer que façam é de implicação espiritual. Por isso, o cuidado perfeccionista com os excessos. O silêncio, que ao mesmo tempo revela a importância da palavra, também abre para outros caminhos no universo de vivenciar as trocas, as concentrações, as conexões com as formas de vidas. Ele é infinitamente mais presente que na vida da cidade, e com ele, nas comunidades, começase a descobrir sua densidade e a legitimidade dos outros modos de ler e dizer da vida. Antes de falar, por exemplo em situações coletivas, os Guarani desejam "belas palavras". A palavra plena é a formulação última de Lacan (1996) sobre os momentos do tratamento em que existe um alto nível de coerência com a verdade de cada 
um, sendo que este é enunciado na fala. A consideração à palavra e ao silêncio é algo que une os cuidadores clínicos e os Guarani.

O filósofo equatoriano Arias (2011) trata do coraçonar a espiritualidade, a vida, a política, assim apostando na decolonização da alma. Diz que a espiritualidade é a resposta política mais alta. E todos esses elementos, em especial o falar desde a sabedoria do coração, posicionamse, enquanto estratégia cosmo-existencial, para a luta. Também retomam os ensinamentos Guarani:

\begin{abstract}
Que debemos mantener siempre encendido el fuego del corazón para que reviva el espíritu de la palabra, pues solo así podremos reencontrarnos con los demás, con los otros. Pero sobre todo, podremos reencontrarnos con nosotros mismo... Que el espíritu de la palabra, que da vida el fuego del corazón, hará posible que podamos conversar con amor y con respeto, con el espíritu de la tierra, de la naturaleza y el cosmos (KARAI MIRI POTY apud ARIAS, 2011, p. 10).
\end{abstract}

A posição de cuidado com os excessos e de que tudo tem relevância, a consideração à responsabilidade de maneira radial também aproximam cuidadores e os Guarani. Mais que isso. O povo Guarani localiza valor em todo e qualquer ato e, ao mesmo tempo, relativiza esse peso. O que se quer dizer é que a noção de imperfeição, de falta e de todas as outras é sempre cuidada. No entanto, exercem um cuidado orgânico para que o que remonta à falta em alguém jamais o reduza a ela. As práticas cotidianas de valorização dos predicados de cada um, em uma busca por colocá-lo em seu melhor caminho, aquele para o qual nasceu, fazendo aparecer o seu melhor, são frequentes, ao mesmo tempo em que os exercícios de leitura crítica e correção das imperfeições chegam a níveis talvez não suportáveis pelos mestiços.

A filosofia para a vida, a educação para a saúde, a compreensão dos males e dificuldades enquanto aspectos ligados a dimensões sutis e jamais resolvíveis, como algo não concernente à alma, são questões que proporcionam a aproximação. Para, além disso, quando Lacan ensina que a resistência, no caso ao tratamento, significa força simbólica, deseja-se perguntar aos Guarani como fortalecer o resistir, o simbólico, os modos de estar que privilegiam o estar vivo enquanto valor maior e seus usufrutos.

O distanciamento da escrita, da dimensão da burocracia, da institucionalização, do acúmulo capitalista e do controle sobre o outro e a valorização da palavra falada são aspectos que se tem em comum quanto aos cuidados com a saúde mental. Deseja-se perguntar como estruturar ou que caminhos são possíveis para se criar um modo de dialogar respeitando ambos os horizontes culturais.
Costuma-se pensar que um psicanalista somente o é quando de sua prática em atendimentos clínicos. Fora isso, o que ocorre é que se localiza que há um psicanalista ali, onde realiza suas discussões na universidade, nos trabalhos em equipe, no social. Nesse caso, o campo de intercâmbio com outras culturas, que pode ocorrer nas comunidades, na cidade, nas estradas que ligam ambas, nas redes sociais, é um campo de convivência humana fora do enquadramento clínico. O que permanece, no entanto, e possivelmente seja o mais importante em todos os casos, é a escuta e o simbólico que persiste em questão.

Para se estar em campo, coabitando com um povo, como se sabe, é preciso uma convivência extensa e de qualidade absolutamente diferente do encontro no consultório e de todos os seus artifícios, mesmo que sejam eventualmente transpostos para um hospital, corredor de uma instituição ou atendimento domiciliar. As paredes, o divã ou até mesmo o tempo lógico, dessa vez, é o que se leva no coração, o que se intui nas vozes, nas neblinas e nos sinais que aparecem no céu e que sinalizam caminhos nessas convivências.

Aprende-se cotidianamente que o tempo da cidade e das comunidades originárias são obviamente diversos. O ritmo acelerado das falas, do trânsito, a naturalização da artificialização da vida aparece, e um dos primeiros elementos é a questão temporal. Uma reunião de equipe, seja na aldeia, seja nas visitas a esta, seja na cidade, apresenta sempre a cena de visibilização e audição dos níveis diferentes de vivenciar o ritmo do universo. Aos poucos, e este é um dos grandes primeiros exercícios, vai-se educando para escutar a velocidade que se empreende e em que ela é colocada, a qualidade das expressões de fala, da postura do corpo, da estética, o valor de retomar ou formular o lugar do silêncio e a relativização do que já havia trazido alienação há muito tempo.

Alex, vice-cacique de Estrela Velha, em sala na disciplina de Psicologia Comunitária I, na Unisc, contou emocionado sobre sua tentativa de viver como os não indígenas, afirmando que começou a sair da aldeia às cinco da manhã para trabalhar. Ficava muito tempo longe da comunidade e dava presentes a sua filha: um tablet, exemplificou. Um tempo depois, quando percebeu que ela quase não o usava, conversou com sua filha que lhe disse preferir mesmo que ele estivesse presente no seu dia a dia, ensinando sobre o plantio do milho e sobre outras coisas da sua cultura. "Aprender com afeto, convivendo." Foi assim, afirmou ele emocionado, que abandonou a sua ideia de trabalhar, como se pratica e se entende trabalho, e voltou a viver de acordo com o que acredita, com a sua cultura.

O tempo do fazer para ser, para acumular, para avançar com rapidez, vai dando lugar à urgência do tempo da convivência, do estar, das trocas com a vida, nos níveis 
diversos, suas sutilezas, e aí vai se alterando a ideia de produção. Quando se passa a substituir uma reunião de três horas, por exemplo, pelo trabalho ao longo de um dia inteiro de permanência em uma comunidade, vê-se se esvair uma série de hábitos. A partir de momentos de algumas falas dos sábios, de experiências com a natureza tomadas como ensinamentos, de elementos que são presenciados na educação cotidiana, chega-se ao final do dia com um vasto material produzido, de valor raro e absolutamente construído por outros vieses de pensamento, compreensão e efeitos transmutativos.

Aprende-se a cuidar o olhar, o tom de voz, os imperativos, a passividade, todo tipo de excesso de intensidade, inclusive o excesso do próprio cuidado. Aprende-se que o modo de se alimentar pode ser algo visto como muito lento, com excesso de fala, que as urgências pulsionais e corporais de modo geral são vivenciadas na cidade como imperativos exagerados. Aprende-se que descansar não é dormir muitas horas. Inclusive para isto existe um tempo regulador no universo, o do sol. Cogitar deixar de lado esse regulador pode ser um ato de grande desrespeito. Mesmo aos domingos e feriados.

Em reuniões na aldeia, no campo da pesquisa "Infâncias e educação Guarani", enquanto se discutia com os participantes da pesquisa, nas histórias de crianças que foram escritas no livro sobre suas infâncias, foi-se percebendo o quanto existe uma dimensão simbólica na leitura do trovão. Sendo este associado a uma forma de comportamento raivoso, a um ato reflexivo de pensar a partir do simbólico, em contrapartida ao modo desenraizado da cultura ocidental.

Para os não indígenas, não existe valor na montanha, na natureza, na chuva, não existem sentidos e significados simbólicos que ajudem no balanço entre a parte e a totalidade, ou que ajudem a simplesmente vivenciar. A psique, conforme Jung (2011), está fragilizada, desprovida da capacidade de simbolizar. Os seres humanos estão isolados do cosmos, sem envolvimento com a natureza e sem envolvimento emocional nos fatos naturais. Falta espírito nos rios, nas casas, na chuva, no coração. Para Jung (2007), o ser humano, ao defrontar-se com o espírito, leva a conquista não só da natureza, como também do espírito, mesmo que não se dê conta do que está acontecendo.

Percebe-se que o conforto das acomodações que vieram com o Ocidente e com a indústria podem ser metáforas para vivências que se distanciam de algumas sacadas sobre o quão direta e implacável pode ser a verdade, a vida e seus limites. Um outro elemento que invariavelmente surge enquanto confrontador, talvez das heranças burocráticas e de traços procrastinadores, é a relevância das efetivações. Se, de projetos, de ideias mencionadas nas palavras ou de endereçamentos nas trocas, o que é sinalizado não é efetivado, aprende-se que isso pode não ser muito bem-visto.

As perguntas inevitáveis sobre os limites das aprendizagens nas fronteiras, das responsabilidades e da contribuição são frequentes. Nos trabalhos em equipe, não raro a inquietação, em seus níveis nem sempre mais suaves, vem a pergunta sobre o lugar que se ocupa, sobre os riscos dos projetos, sobre as incompreensões do lado das instituições urbanas e, quem sabe, sobre qual exatamente é esse lugar que se ocupa. Detalhar os contornos dessa continuidade entre a vida das comunidades, a ancestralidade, as antropofagias para ambos os lados e de que ponto específico cada profissional pode responder para colaborar e dar seu melhor, é tema para se produzir.

Tem-se uma hipótese de que os pilares pleiteados pela psicanálise, do sexual e da finitude, são estruturas cruciais para serem revistas em relação aos modos de viver que fazem com que se situe mais do lado de elementos ancestrais. E estes compreendem a vivência das trocas mais pelo viés da poligamia e da coletividade e pela finitude amplamente ligada a questões espirituais. Já do lado ocidental, a noção de propriedade, a monogamia e o viés científico e de controle de aspectos físicos e emocionais de modo categorizado marcam seus vetores com respeito à finitude.

Nesse sentido, também cabe a cada um caminhar com seus limites formulados sobre o quão mais ou menos perto desses vetores de um ou de outro lado se está. Acima de tudo, pensa-se que, assim como Lacan (1988) ensina que se recebe do outro semprea mensagem invertida, no encontro com oráculo originário, com muita rapidez se entende que se é confrontado coma própria questão. Por motivo que ainda caberá refletir mais, a aproximação de um povo milenar costuma lançar-se sempre em uma rigorosa confrontação com as próprias verdades. O que ali aparecer enquanto paixão e dificuldade pode ser o enigma de vida a resolver.

\section{REFERÊNCIAS}

ARIAS, Patricio. Corazonar la dimensión política de la espiritualidad y la dimensión espiritual de la política. Revista de Ciências Humanas Sociales y Educación. Universidad Politécnica Salesiana del Equador. Quito,v. 10, p. 21-39, janeiro-junho de 2011.

BERGAMASCHI, Maria Aparecida; MENEZES, Ana Luisa Teixeira de. Educação ameríndia: a dança e a escola ameríndia. 2. ed. Santa Cruz do Sul: EDUNISC, 2015. [1. ed.: 2009].

BERGÈS, Jean; BALBO, Gabriel. O jogo de posições mãecriança. Ensaio sobre o transitivismo. Porto Alegre: CMC, 2002.

CAMPBELL, Joseph. O poder do mito. São Paulo: Palas Athena, 1990.

JECUPÉ, Kaká Werá. Todas as vezes que dissemos adeus. São Paulo: Triom, 2002. 
JUNG, Carl Gustave. Os arquétipos e o inconsciente coletivo. 5. ed. Tradução Maria Luiza Appy e Dora Mariana R. Ferreira da Silva. Petrópolis, RJ: Vozes, 2007.

JUNG, Carl Gustave. A vida simbólica: escritos diversos. 18/1. 5. ed. Petrópolis, RJ: Vozes, 2011.

JUNG, Carl. Gustave. Aion - estudo sobre o simbolismo do si-mesmo. Tradução de Dom Mateus Ramalho Rocha. 10. ed. Petrópolis, RJ: Vozes, 2013.

KUSCH, Rodolfo. América profunda. Córdoba: Editorial Fundación Ross, 2000.

KUSCH, Rodolfo. Obras completas. Rosário: Fundacion Ross, 2006.

LACAN, Jacques. Seminário 1. Os escritos técnicos de Freud. Rio de Janeiro: Jorge Zahar, 1996.

LACAN, Jacques. Seminário 3. As psicoses. Rio de Janeiro: Jorge Zahar, 1988.

LITTLE, Paul E. Conhecimentos tradicionais para o século XXI: etnografias da intercientificidade. São Paulo: Annablume, 2010.

MENEZES, Ana Luisa Teixeira de; RICHTER, Sandra Regina Simonis. Infância e educação Guarani: para não esquecer a palavra. Revista Tellus, Campo Grande, n. 26, p. 101-118, out. 2014.

MENEZES, Ana Luisa Teixeira; RICHTER, Sandra Regina Simonis; SILVEIRA, Viviane Fernandes et al. Nhandereko Kue Kyringue'í Reko Rã - nossa história para as crianças. Porto Alegre: Imprensa Livre, 2015.
MIGNOLO, Walter D. Os esplendores e as misérias da "ciência": colonialidade, geopolítica do conhecimento e pluriversalidade epistêmica. In: SANTOS, Boaventura de Sousa (org.). Conhecimento prudente para uma vida decente: um discurso sobre as ciências revisitado. São Paulo: Cortez, 2006.

POTY, Vherá; CHRISTIDIS, Danilo. Os Guarani Mbyá. Porto Alegre: Wences Design Criativo, 2015.

SANTOS, Boaventura de Sousa. Um ocidente não ocidentalista. A filosofia à venda, a douta ignorância e a aposta de Pascal. In: SANTOS, Boaventura de Sousa (org.). Conhecimento prudente para uma vida decente: um discurso sobre as ciências revisitado. São Paulo: Cortez, 2010.

RIBEIRO, Darcy. O povo brasileiro. A formação e o sentido do Brasil. Rio de Janeiro: Cia. das Letras, 1995.

ROSSI, Alejandro. Maestria em créación musical, nuevas tecnologias y artes tradicionales. Seminário Geocultura del gesto creador. Buenos Aires: UNTREF; 2014 (comunicação oral).

TASAT, José Alejandro. El hedor en el pensamoento de Rodolfo Kusch. In: TASAT, José Alejandro; PÉREZ, Juan Pablo (Orgs.). El hedor de América. Reflexiones interdisciplinarias a 50 años de la América profunda de Rodolfo Kusch. Ciudad Autônoma de Buenos Aires: Ediciones del CCC, 2013.

Submetido em: 20/01/2016

Aprovado em: 26/01/2016 